\title{
Mechanical Characterization and FE Modelling of a Hyperelastic Material
}

\author{
Majid Shahzad *, Ali Kamran ${ }^{b}$, Muhammad Zeeshan Siddiqui ${ }^{a}$, Muhammad Farhan \\ ${ }^{a}$ Advance Materials Research Directorate, Space and Upper Atmosphere Research Commission- \\ SUPARCO, Karachi, Sindh, Pakistan \\ ${ }^{b}$ Institute of Space Technology - IST, Islamabad Highway, Islamabad, Pakistan
}

Received: August 25, 2014; Revised: July 29, 2015

\begin{abstract}
The aim of research work is to characterize hyperelastic material and to determine a suitable strain energy function (SEF) for an indigenously developed rubber to be used in flexible joint use for thrust vectoring of solid rocket motor. In order to evaluate appropriate SEF uniaxial and volumetric tests along with equi-biaxial and planar shear tests were conducted. Digital image correlation (DIC) technique was utilized to have strain measurements for biaxial and planar specimens to input stress-strain data in Abaqus ${ }^{\circledR}$. Yeoh model seems to be right choice, among the available material models, because of its ability to match experimental stress-strain data at small and large strain values. Quadlap specimen test was performed to validate material model fitted from test data. FE simulations were carried out to verify the behavior as predicted by Yeoh model and results are found to be in good agreement with the experimental data.
\end{abstract}

Keywords: hyperelastic material, DIC, Yeoh model, FEA, quadlap shear test

\section{Introduction}

Hyperelastic materials such as rubber are widely used for diverse structural applications in variety of industries ranging from tire to aerospace. The most attractive property of rubbers is their ability to experience large deformation under small loads and to retain initial configuration without considerable permanent deformation after load is removed ${ }^{1}$. Their stress-strain behaviour is highly non-linear and a simple modulus of elasticity is no longer sufficient. Therefore, characterization of elastic behaviour of highly extensible, nonlinear materials is of great importance ${ }^{2}$.

The constitutive behaviour of hyperelastic material is derived from SEF ' $W$ ' based on three strain invariants $I_{1}, I_{2}$ and $I_{3}$. It is the energy stored in material per unit of reference volume (volume in the initial configuration) as a function of strain at that point in material ${ }^{3}$.

$W=f\left(I_{1}, I_{2}, I_{3}\right)$

where $I_{1}, I_{2}$ and $I_{3}$ are three invariants of Green deformation tensor defined in terms of principal stretch ratios $\lambda_{1}, \lambda_{2}$ and $\lambda_{3}$ given by ${ }^{4}$ :

$I_{1}=\lambda_{1}^{2}+\lambda_{2}^{2}+\lambda_{3}^{2}$

$I_{2}=\lambda_{1}^{2} \lambda_{2}^{2}+\lambda_{2}^{2} \lambda_{3}^{2}+\lambda_{3}^{2} \lambda_{I}^{2}$

$I_{3}=\lambda_{1}^{2} \lambda_{2}^{2} \lambda_{3}^{2}$

Generally, hyperelastic materials are considered incompressible, i.e. $I_{3}=1$; hence only two independent strain measures namely $I_{1}$ and $I_{2}$ remain. This implies that ' $W$ ' is a function of $I_{1}$ and $I_{2}$ only';

$W=W\left(I_{1}-3, I_{2}-3\right)$

*e-mail: dr_majid@engineer.com
The selection of suitable SEF depends on its application, corresponding variables and available data for material parameter identification ${ }^{5}$. Chagnon et al. ${ }^{6}$ described four main qualities of an efficient hyperelastic material model as follows:

- It should have the ability to exactly reproduce the entire ' $\mathrm{S}$ ' shaped response of rubber

- The change of deformation mode should not be problematic, i.e. if the model operates satisfactorily in uniaxial tension, it must also be satisfactory in simple shear or in equibiaxial extension

- The number of fitting material parameters should be small, in order to decrease the number of experimental tests needed for their determination

- The mathematical formulation should be simple to render possible the numerical implementation of the model.

For a precise prediction of rubber behaviour, used in an assembly (e.g. flexible joint), by finite element simulation, it should be tested under same loading conditions to which original assembly will be subjected. The uniaxial tests are easy to perform and are well understood ${ }^{7}$ but uniaxial data alone does not produce reliable set of coefficients for material models ${ }^{8}$, especially if the original assembly experiences complex stress states. Therefore, biaxial, planar (pure shear) and volumetric tests need to be performed along with a uniaxial tension test to incorporate the effects of multiaxial stress states in the model.

For specific applications, the tailoring of rubber mechanical properties is carried out by the addition of various chemicals. 
Minor changes in chemical composition can alter mechanical properties significantly. Therefore, it is essential to test a particular rubber composition and simulate through FEA to have an apposite SEF. Once determined, this can be used for simulating the assembly in which particular rubber has been used. FE software packages like Abaqus ${ }^{\circledR}$ offer a number of SEFs to accommodate the nonlinear behavior of rubber and other hyperelastic materials. This study shows that Yeoh model has an advantage over other available material models because of its good match with experimental data over large strain values for given rubber composition.

\section{Hyperelastic Models in Abaqus}

In Abaqus ${ }^{\circledR}$, two types of hyperelastic material models are available and each model defines the strain energy function in a different way ${ }^{9}$. One is the phenomenological models which treat the problem from the viewpoint of continuum mechanics and stress-strain behaviour is characterized without reference to the microscopic structure. Other one is physically motivated models which consider the material response from the viewpoint of microstructure. A brief review about the hyperelastic models available in Abaqus ${ }^{\circledR}$ exploited during this study is given below.

\subsection{Mooney-Rivlin model}

Two parameters phenomenological model that works well for moderately large stains in uniaxial elongation and shear deformation ${ }^{10,11}$. But, it cannot capture the upturn (S-curvature) of the force-extension relation in uniaxial test and the force-shear displacement relation in shear test. For a compressible rubber, model has a form

$$
W=C_{10}\left(\bar{I}_{1}-3\right)+C_{0 I}\left(\bar{I}_{2}-3\right)+\frac{1}{D_{1}}\left(J_{e l}-1\right)^{2}
$$

\subsection{Neo-Hookean model}

This model is a special case of Mooney-Rivlin form with $C_{01}=0$ and can be used when material data is insufficient. It is simple to use and can make good approximation at relatively small strains. But, it too cannot capture the upturn of stress strain curve.

$$
W=C_{l 0}\left(\bar{I}_{1}-3\right)+\frac{1}{D_{l}}\left(J_{e l}-1\right)^{2}
$$

\subsection{Full Polynomial model}

For isotropic and compressible rubber, polynomial model can be given as

$$
W=\sum_{i, j=0}^{N} C_{i j}\left(\bar{I}_{l}-3\right)^{i}\left(\bar{I}_{2}-3\right)^{j}+\sum_{i=1}^{N} \frac{1}{D_{i}}\left(J_{e l}-1\right)^{2 i}
$$

Where:

$C_{\mathrm{ij}}=$ material constants that control the shear behaviour and can be determined from uniaxial, biaxial and planar tests. $D_{\mathrm{i}}=$ material constant that control bulk compressibility and set to zero for fully incompressible rubber. It can be estimated from volumetric test.

$J_{\text {el }}=$ Elastic volume ratio

$\mathrm{N}=$ Number of terms in strain energy function. Abaqus allows up-to 6 terms.

\subsection{Reduced Polynomial model}

This model does not include any dependency on $I_{2}$. The sensitivity of strain energy function to variation in $I_{2}$ is generally much smaller than the sensitivity to variation in $I_{1}$. It appears that eliminating the terms containing $I_{2}$ from strain energy function improves the ability of the models to predict the behaviour of complex deformation states when limited test data is available ${ }^{12}$. The Neo-Hookean form is first order reduced polynomial model.

\subsection{Yeoh model}

In 1993, Yeoh ${ }^{13}$ proposed a phenomenological model in the form of third-order polynomial based only on first invariant $I_{1}$. It can be used for the characterization of carbon-black filled rubber and can capture upturn of stress-strain curve. It has good fit over a large strain range and can simulate various modes of deformation with limited data. This leads to reduced requirements for material testing ${ }^{14}$. The Yeoh model is also called the reduced polynomial model and for compressible rubber can be given as

$$
W=\sum_{i=1}^{3} C_{i 0}\left(\bar{I}_{l}-3\right)^{i}+\sum_{i=1}^{3} \frac{1}{D_{i}}\left(J_{e l}-1\right)^{2 i}
$$

\subsection{Ogden model}

Proposed in 1972 by Ogden ${ }^{15,16}$, this is also a phenomenological model and is based on principal stretches instead of invariants. The model is able to capture upturn (stiffening) of stress-strain curve and models rubber accurately for large ranges of deformation. Attention should be paid not to use this model with limited test (e.g. just uniaxial tension). A good agreement has been observed between Ogden model and Treloar's ${ }^{17}$ experimental data for unfilled rubber for extensions up to $700 \%$.

$W=\sum_{i=1}^{N} \frac{2 \mu_{i}}{\alpha_{i}^{2}}\left(\bar{\lambda}_{l}^{\alpha_{i}}+\bar{\lambda}_{2}^{\alpha_{i}}+\bar{\lambda}_{3}^{\alpha_{i}}-3\right)+\sum_{i=1}^{N} \frac{1}{D_{i}}\left(J_{e l}-1\right)^{2 i}$

$\bar{\lambda}_{i}$ is the deviatoric principal stretch and $\mu_{i}, \alpha_{i}$ are temperature dependent material properties. Abaqus allows up to $N=6$ terms in the above form.

\subsection{Arruda-Boyce model}

Based on molecular chain network, it is also called Arruda-Boyce 8-chain model because it was developed based on representative volume (hexahedron) element where 8 chains emanate from the center to the corners of the volume ${ }^{18}$. This is two parameter shear model based only on $I_{1}$ and works well with limited test data.

$$
W=\mu \sum_{i=l}^{5} \frac{C_{i}}{\lambda_{m}^{2 i-2}}\left(\bar{I}_{l}^{i}-3^{i}\right)+\frac{1}{D}\left(\frac{J_{e l}^{2}-1}{2}-\ln \left(J_{e l}\right)\right)
$$

\section{Experimental Details}

\subsection{Material}

Natural rubber reinforced by carbon-black was used for this research work whose chemical composition is given in Table 1. The nominal rubber mechanical properties as determined by various tests are given in Table 2 . 
Table 1. Chemical composition of rubber.

\begin{tabular}{cccccc}
\hline $\begin{array}{c}\text { Natural Rubber } \\
(\mathbf{g m s})\end{array}$ & $\begin{array}{c}\text { Carbon-Black } \\
(\mathbf{g m s})\end{array}$ & $\begin{array}{c}\text { Stearic Acid } \\
(\mathbf{g m s})\end{array}$ & $\begin{array}{c}\text { Zinc Oxide } \\
(\mathbf{g m s})\end{array}$ & $\begin{array}{c}\text { MBT } \\
(\mathbf{g m s})\end{array}$ & $\begin{array}{c}\text { Sulphur-80 } \\
(\mathbf{g m s})\end{array}$ \\
\hline 100 & 40 & 6 & 3 & 1 & 1 \\
\hline
\end{tabular}

Table 2. Mechanical properties of rubber calculated by different tests.

\begin{tabular}{cccc}
\hline $\begin{array}{c}\text { Tensile } \\
\text { Strength } \\
(\mathbf{M P a})\end{array}$ & $\begin{array}{c}\% \\
\text { Elongation }\end{array}$ & $\begin{array}{c}\text { Shear } \\
\text { Strength } \\
(\mathbf{M P a})\end{array}$ & $\begin{array}{c}\text { Shear } \\
\text { Modulus } \\
(\mathbf{M P a})\end{array}$ \\
\hline 12 & 610 & 4.6 & 0.36 \\
\hline
\end{tabular}

\subsection{Mechanical testing}

This section describes the standard tests performed to input stress-strain data into Abaqus ${ }^{\circledR}$ to evaluate the material constants for different hyperelastic models. Since the models use a simple reversible stress strain input, one must input a stress strain function that is relevant to the loading condition expected in the application.In order to avoid variation of mechanical properties between rubber characterization results and specific application, all rubber specimens were manufactured from the same batch with identical curing cycles. The curing cycle parameters were same as that of flexible joint.

\subsubsection{Uniaxial test}

The test was performed on dumbbell shaped specimens prepared according to Type IV ASTM D638 ${ }^{[19]}$. Testing was carried out on Lloyd LR10K Material Testing Machine and load was measured using $5 \mathrm{kN}$ load-cell whereas displacement was measured using extensometer (Figure 1). Initially, rubber specimen was subjected to 20 load cycles in the strain range of $0-400 \%$ to get stabilized data. For an engineering analysis, it may be more worthwhile to have precise stress strain measurements in the range of interest rather than to study the strain at failure. Test was performed at ambient conditions and strain rate was selected to be $100 \mathrm{~mm} / \mathrm{min}$.

\subsubsection{Volumetric test}

Volumetric compression fixture consists of punch, die and alignment cap as shown in Figure 2a. The rubber sample was molded in the die which was designed to sit on bottom compression jig of machine. Alignment cap is fastened on the die to provide an initial envelop for the punch to align itself and also to ensure that mating surfaces of punch and rubber specimen are parallel to each other. Punch was manually inserted in the alignment cap and then pre-load of $50 \mathrm{~N}$ was applied through machine to fix the assembly. Stabilization of rubber specimen was achieved through cyclic test which consists of 20 cycles in the extension range of $0-1.5 \mathrm{~mm}$. Then the specimen was compressed up-to a force of $9 \mathrm{kN}$ at test speed of $5 \mathrm{~mm} / \mathrm{min}$ and load-extension data was acquired from Nexygen software coupled with machine. From this data, pressure and volume ratio were calculated to input in Abaqus $^{\circledR}$. An approximate linear relationship was observed between pressure and volume ratio up to $115 \mathrm{MPa}$ (Figure 2b) as observed by Bradely et al. ${ }^{20}$ for a carbon-black filled rubber used in elastomeric bearing.

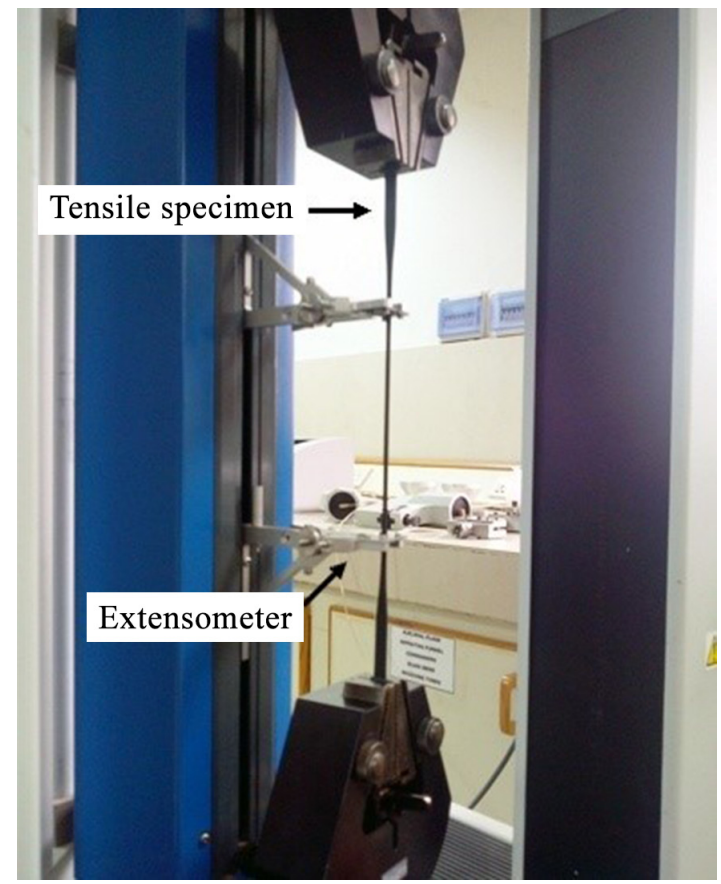

Figure 1. Uniaxial tensile specimen mounted on machine.

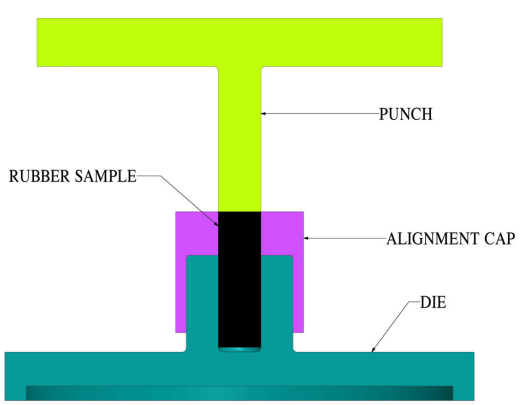

(a)

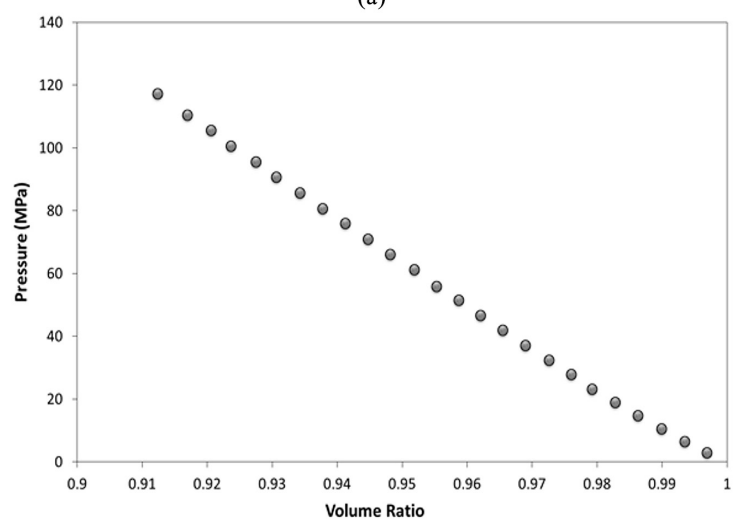

(b)

Figure 2. (a) Volumetric test fixture CAD model; (b) Experimental data of volumetric test. 


\subsubsection{Planar shear test}

The rubber specimen was cold bonded with metallic strips which are the primary connection. Nuts and bolts were used as secondary reinforcement for the fixture and a $15 \mathrm{~mm}$ grip separation was maintained with an aspect ratio of 10. According to Duncan et al. ${ }^{7}$ stress-strain curves are not influenced by grip separation at aspect ratios ranging from 4 to 10 . As previous tests, rubber stabilization was achieved with 20 cycles in the extension range of $0-30 \mathrm{~mm}$ at test speed of $100 \mathrm{~mm} / \mathrm{min}$ and then the specimen was stretched until fracture. The pull force was recorded using a $10 \mathrm{kN}$ load cell. The strain data was carefully checked through DIC for potential debonding or slippage at the rubber metal interfaces. The test setup is shown in Figure 3. A Nikon D90 high resolution CCD camera was placed in front of the specimen to record the test. The camera was carefully aligned such that the specimen surface was approximately parallel to the image plane. A fine speckle pattern was applied to the specimen surface prior to testing.

An indigenously developed DIC system was used to analyze the recorded video ${ }^{21}$. The system was developed in MATLAB under a separate study and used Levenberg Marquardt algorithm for image correlation. The optical methods for strain measurement are best suited for such applications because the measurement is done remotely without interfering with the flexible specimen geometry or any additional load application. Many researchers ${ }^{8,22,23}$ have used a similar technique to measure strains in hyperelastic rubber-like materials.

Upon inspection it was found that as long as the bond between metal and rubber remained intact, the total extension in rubber as measured from DIC was identical to the machine extension. In case the bond failed, the specimen geometry and aspect ratios were so varied, due to the arbitrary shape of bond failure, that the relation between initial specimen geometry and test data was no longer valid. Hence it was decided to observe each specimen during extension for any sign of slippage at the rubber metal interface. For specimens with no slippage or debond, the machine extension was directly used for strain measurement for total strain in the specimen.

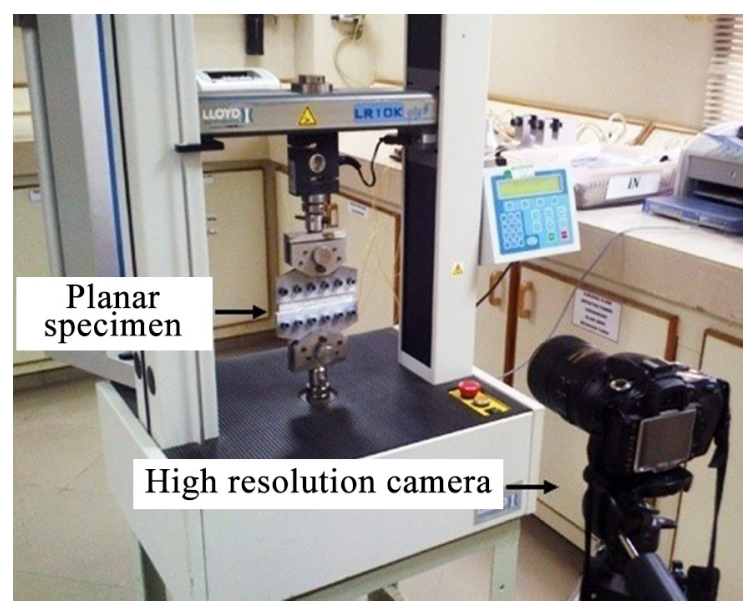

Figure 3. DIC setup for strain measurements in planar specimen.

\subsubsection{Biaxial test}

Biaxial scissor arm fixture was developed to be used with tensile testing machine. The idea of this fixture was taken from Duncan et al. ${ }^{7}$ Additionally this article establishes relationship of force per grip. If each arm has a force $\mathrm{F}$, then the force transferred to the grip is $135 \%$ of force. Rubber specimen is coated with thin layer of spray paint then another color is used to make a random pattern. Arm-sat 45 degrees to the machine axis were stretched at a speed of $100 \mathrm{~mm} / \mathrm{min}$, perpendicular directions, providing biaxial tension state, as shown in Figure 4.

\section{Experimental Results and Curve Fitting for SEF Selection}

The hyperelastic material curve fitting capability in Abaqus $^{\circledR}$ allows user to compare different hyperelastic material models with the test data. In Abaqus ${ }^{\circledR}$, the test data are specified as nominal stress-nominal strain data pairs for uniaxial, planar and biaxial tests to determine the shear constants $C_{\mathrm{ij}}$ and to determine the compressibility constants $D_{\text {ij }}$, pressure-volume ratio data can be specified for volumetric test data. For each stress-strain data pair Abaqus ${ }^{\circledR}$ generates an equation for the stress in terms of the strain invariants or stretches and the unknown hyperelastic constants ${ }^{9}$. The test data, for different deformation modes, were specified and hyperelastic material models were evaluated to fit with experimental data as shown in Figures 5-8. The Yeoh model appeared to be most suitable choice for predicting the behavior of given rubber composition because of its ability to match experimental data points at small and large strain values. The coefficients of Mooney-Rivlin, Neo-Hookean, Yeoh model, Arruda-Boyce and Ogden models as calculated by Abaqus ${ }^{\circledR}$, are given in Tables 3-7 with their average $\mathrm{R}^{2}$ values for all deformation modes.

Table 3. Coefficients of Mooney-Rivlin material model.

\begin{tabular}{cccc}
\hline$C_{10}(\mathbf{M P a})$ & $C_{\mathbf{0 1}}(\mathbf{M P a})$ & $\boldsymbol{D}_{\mathbf{1}}$ & $\mathbf{R}^{2}$ \\
\hline 0.3339 & $-3.37 \mathrm{e}^{-4}$ & $1.5828 \mathrm{e}^{-3}$ & 0.9881 \\
\hline
\end{tabular}

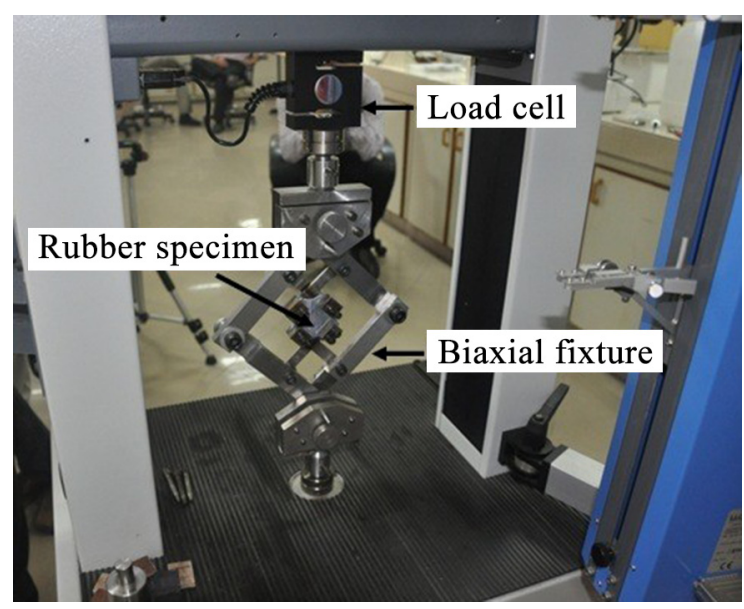

Figure 4. Test fixture to produce equibiaxial stresses in rubber specimen. 


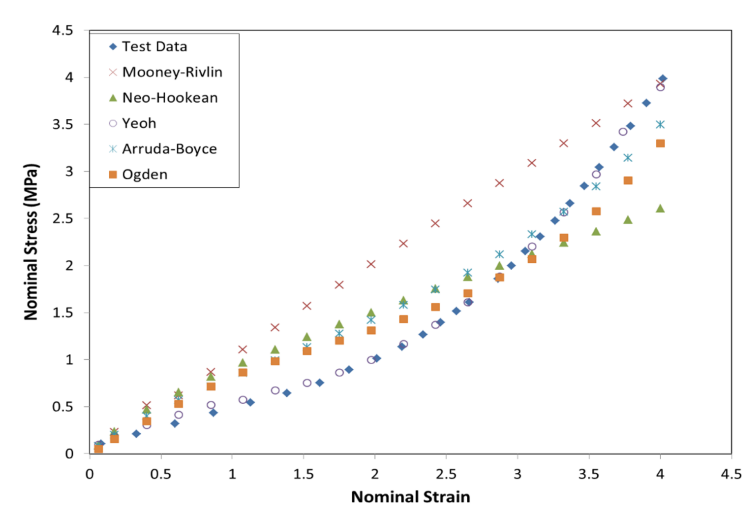

Figure 5. Fitting of different hyperelastic models with uniaxial data.

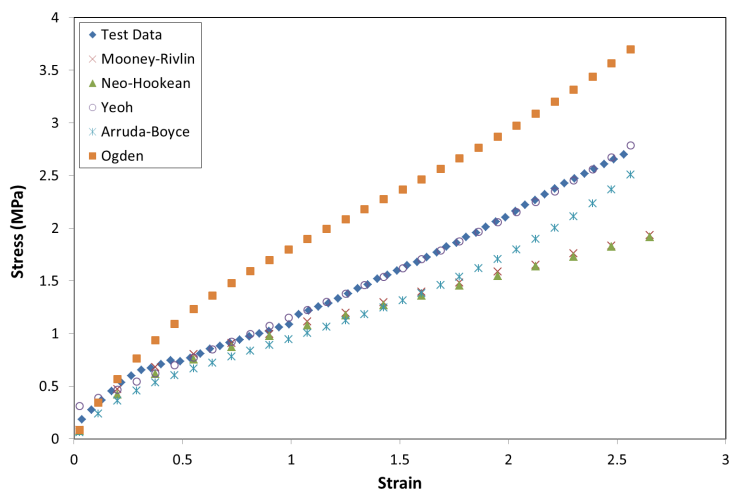

Figure 6. Fitting of different hyperelastic models with biaxial data.

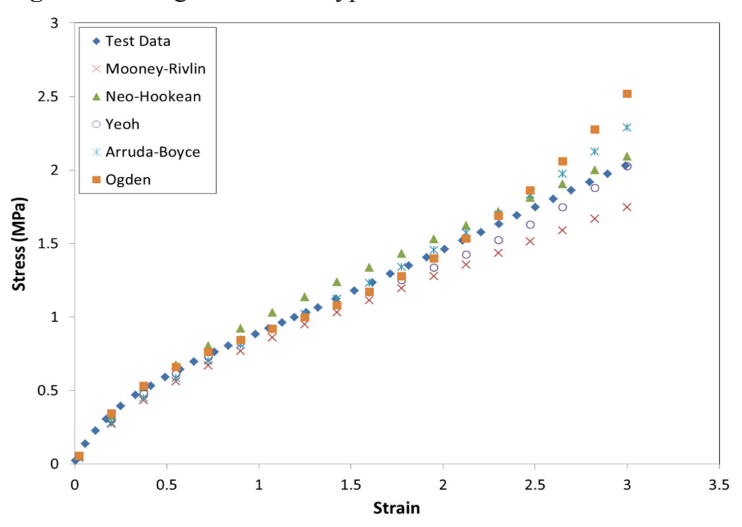

Figure 7. Comparison of different hyperelastic modelswith test data for planarspecimen.

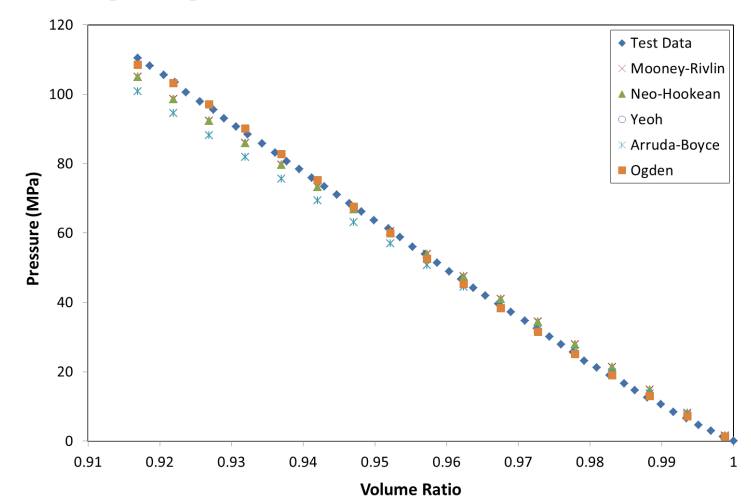

Figure 8. Comparison of different hyperelastic modelswith test data for volumetric experiment.
Table 4. Coefficients of Neo-Hookean material model.

\begin{tabular}{ccc}
\hline$C_{10}(\mathbf{M P a})$ & $\boldsymbol{D}_{\mathbf{1}}$ & $\mathbf{R}^{\mathbf{2}}$ \\
\hline 0.2587 & $1.5828 \mathrm{e}^{-3}$ & 0.9710 \\
\hline
\end{tabular}

\section{FE Simulation Results and Discussions}

The validation of hyperelastic models with experimental data has been done by many researchers ${ }^{8,24-27}$ by modeling the test specimens in different FE softwares. As mentioned earlier that an efficient hyperelastic material model should be independent of mode of deformation. To validate the Yeoh model coefficients, finite element analysis was performed to predict the force and extension for quadlap (simple shear) and biaxial test specimen in Abaqus ${ }^{\circledR}$.

To get experimental data, quadlap specimen was tested in which four rubber pads were sandwiched between steel plates with adhesive. Thickness of rubber specimen was significantly lower than its width and length in order to minimize bending effects $^{24}$. The testing speed was kept same as that of other tests i.e. $100 \mathrm{~mm} / \mathrm{min}$. For FEA of quadlap test, quadratic hex elements with reduced integration (C3D20R) were used for the model in order to reduce mesh density without affecting solution accuracy. C3D20RH elements were used for rubber pads where $\mathrm{H}$ represents hybrid formulation. As the rubber is nearly incompressible, bulk modulus is much larger than shear modulus, FE solution will result in various errors with normal elements such as small change in displacements will cause extremely large changes in pressure, volume strain locking, etc. In order to overcome such issues, hybrid elements are used in which pressure stress is treated as an independently interpolated solution variable that is coupled with displacement solution through constitutive theory ${ }^{9}$. One end of specimen was constrained i.e. $U x=U y=U z=0$, whereas the opposite end was subjected to a displacement in the stretch direction i.e. $\mathrm{Ux}=60 \mathrm{~mm}$ in steps. Figure $9 \mathrm{a}$ illustrates the experimental setup while Figure $9 b$ shows FE simulation of quadlap specimen and the stress field in rubber pads is shown in Figure 9c. A comparison of experimental results with FE simulation of quadlap specimen has shown a good agreement for load-extension data as shown in Figure 10 with a slight deviation at large strain values.

Finally, the equi-biaxial specimen was also simulated via Abaqus $^{\circledR}$. C3D20RH elements were used for biaxial rubber specimen and displacements were applied at four boundary edges. Figure 11a shows the rubber specimen during testing on machine while Figure $11 \mathrm{~b}$ presents the simulation results of principal logarithmic strains for a total machine displacement of $22 \mathrm{~mm}$. Figure 11c graphically depicts the closeness of the FE approximations to the biaxial load-extension data.

The average RMS error was calculated, as per Equation 10 , to compare experimental load with FE predicted load values and error was found to be $7.2 \%$ in case of quadlap test and $8.6 \%$ for biaxial specimen.

$$
R M S_{\text {avg }} \text { Error }=\frac{1}{N} \sqrt{\sum_{i=1}^{N}\left(\frac{F_{\exp }-F_{F E}}{F_{\exp }}\right)}
$$

$\mathrm{N}$ is the number of points at which load was calculated by FEA. It can be deduced that Yeoh model works well for predicting the behavior in simple shear and biaxial specimen and change of deformation mode is not problematic. 
Table 5. Coefficients of Yeoh, Abaqus ${ }^{\circledR}$ form, material model.

\begin{tabular}{ccccccc}
\hline $\boldsymbol{C}_{\mathbf{1 0}}(\mathbf{M P a})$ & $\boldsymbol{C}_{\mathbf{2 0}}(\mathbf{M P a})$ & $\boldsymbol{C}_{\mathbf{3 0}}(\mathbf{M P a})$ & $\boldsymbol{D}_{\mathbf{1}}$ & $\boldsymbol{D}_{\mathbf{2}}$ & $\boldsymbol{D}_{\mathbf{3}}$ & $\mathbf{R}^{\mathbf{2}}$ \\
\hline 0.2019 & $4.43 \mathrm{e}^{-5}$ & $1.295 \mathrm{e}^{-4}$ & $2.1839 \mathrm{e}^{-3}$ & $8.68 \mathrm{e}^{-5}$ & $-1.794 \mathrm{e}^{-5}$ & 0.9962 \\
\hline
\end{tabular}

Table 6. Coefficients of Ogden, $\mathrm{N}=3$, material model.

\begin{tabular}{cccc}
\hline Mu_I & Alpha_I & D_I & R $^{2}$ \\
\hline 0.4451 & -0.2241 & $1.824 \mathrm{e}^{-3}$ & 0.9896 \\
3.2898 & 4.3753 & $4.596 \mathrm{e}^{-5}$ & \\
2.8917 & -2.783 & $-7.334 \mathrm{e}^{-7}$ & \\
\hline
\end{tabular}

Table 7. Coefficients of Arruda-Boyce material model.

\begin{tabular}{ccccc}
\hline Mu & Mu_O & Lamda_M & D & $\mathbf{R}^{\mathbf{2}}$ \\
\hline 0.4283 & 0.4462 & 3.9142 & $1.712 \mathrm{e}^{-3}$ & 0.9902 \\
\hline
\end{tabular}

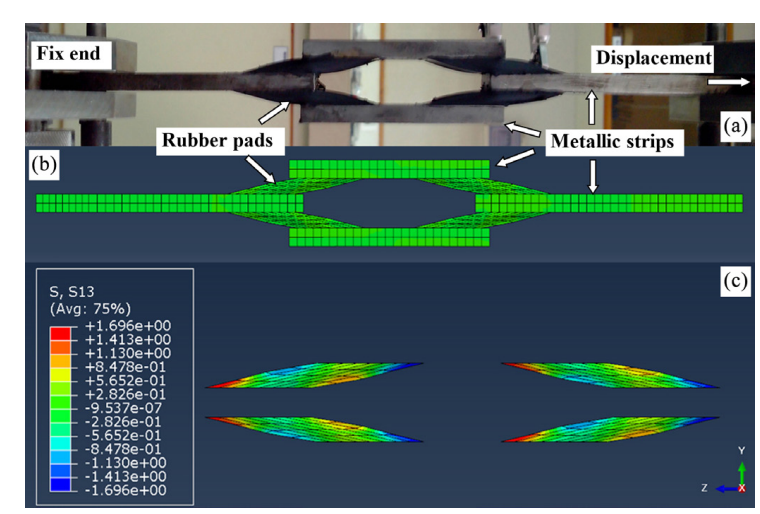

Figure 9. (a) Quadlap shear specimenduring test on machine; (b) FE simulation of quadlap specimen using Abaqus ${ }^{\circledR}$; (c) Shear stress field in rubber pads.

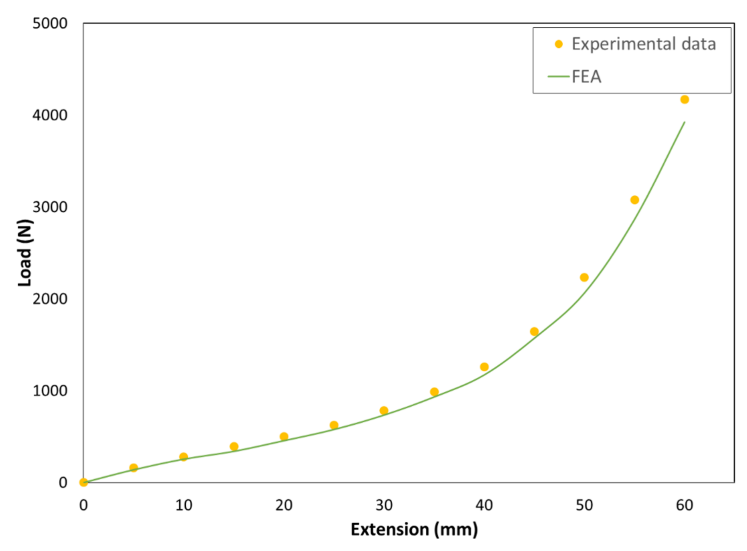

Figure 10. A comparison of FE prediction with experimental data for quadlap specimen.

\section{Conclusions}

In this work, experimental data from four deformation tests were obtained to input into Abaqus ${ }^{\circledR}$ in order to calibrate hyperelastic model coefficients for given rubber behavior. DIC technique was employed for strain measurements in planar and biaxial specimen. Among the number of models available in literature and implemented into commercial FE codes, Yeoh model was found to be the most suitable

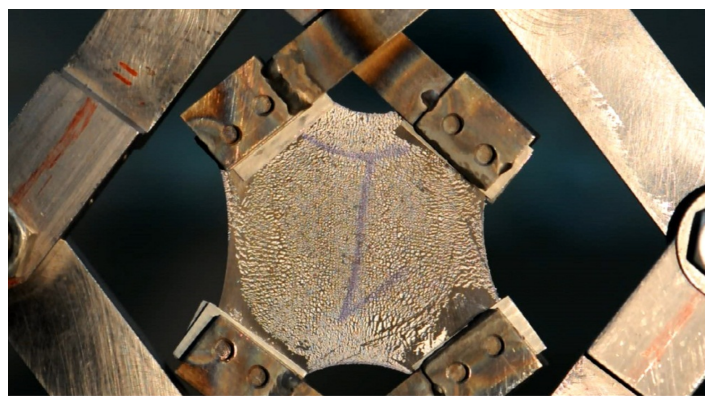

(a)

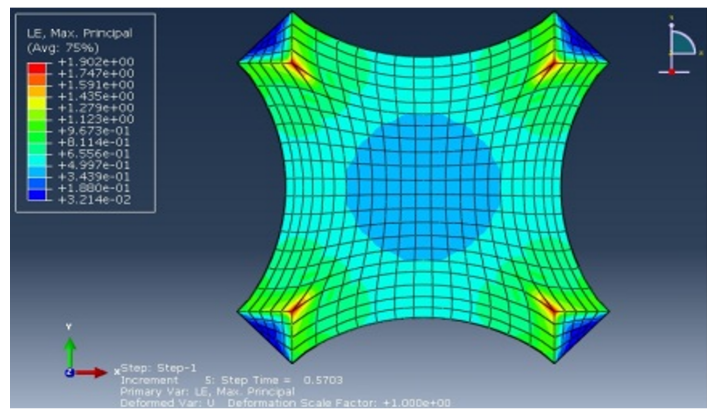

(b)

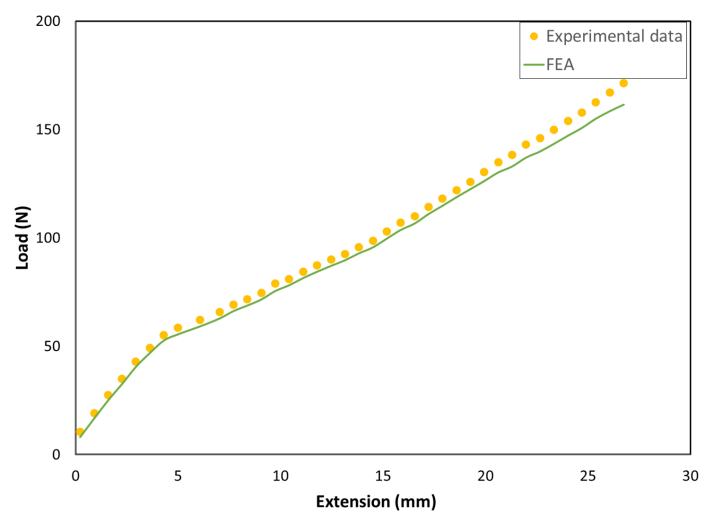

(c)

Figure 11. (a) Stretching of biaxial specimen on machine, (b) FEM simulation of same (c) Comparison between numerical and experimental data.

choice. For the two analyzed deformational states in Abaqus ${ }^{\circledR}$ i.e. equi-biaxial and simple shear, the Yeoh model gives a stable analytical description of the material stress-strain response and a good agreement between numerical and experimental data, even at large values of strains.

\section{Acknowledgements}

The authors would like to acknowledge Chemical Division for preparation of rubber samples and Materials Research Testing Division for carrying out the testing of samples. The authors would also to thank SUPARCO for providing all the resources for this research purpose. 


\section{References}

1. Brinson $\mathrm{H}$ and Brinson L. Polymer engineering science and viscoelasticity: an introduction. Evanston: Springer Verlag; 2008.

2. Gent AN. Engineering with rubber: how to design rubber components. 2nd ed. Munich: Hanser Gardener Publication; 2000.

3. Ali A, Hosseini M and Sahari B. A review of constitutive models for rubber-like materials. American Journal of Engineering and Applied Sciences. 2010; 3(1):232-239. http://dx.doi.org/10.3844/ ajeassp.2010.232.239.

4. Dolwichai P, Limtragool J, Inban S and Piyasin S. In: Hyperelastic Material Models for Finite Element Analysis with Commercial Rubber, Technology and Innovation for Sustainable Development Conference (TISD2006); 2006. Khon Kaen, Thailand. Khon Kaen: Khon Kaen University; 2006. p.769-774.

5. Khajehsaeid H, Arghavani K and Naghdabadi R. A hyperelastic constitutive model for rubber-like materials. European Journal of Mechanics. A, Solids. 2013; 38:144-151. http://dx.doi. org/10.1016/j.euromechsol.2012.09.010.

6. Chagnon G, Marckmann $\mathrm{G}$ and Verron E. A comparison of the Hart-Smith model with Arruda-Boyce and Gent formulations for rubber elasticity. Rubber Chemistry and Technology. 2004; 77(4):724-735. http://dx.doi.org/10.5254/1.3547847.

7. Duncan BC, Maxwell AS, Crocker LE and Hunt R. Verification of hyperelastic test methods. Teddington: NPL; 1999. NPL Report CMMT(A) 226.

8. Sasso M, Palmieri G, Chiappini G and Amodio D. Characterization of hyperelastic rubber-like materials by biaxial and uniaxial stretching tests based on optical methods. Polymer Testing. 2008; 27(8):995-1004. http://dx.doi.org/10.1016/j. polymertesting.2008.09.001.

9. Dassault Systèmes. Abaqus 6.12. Analysis user's manual. V. III: materials. Providence: Dassault Systèmes; 2012.

10. Mooney MA. A theory of large elastic deformation. Journal of Applied Physics. 1940; 11(9):582-592. http://dx.doi. org/10.1063/1.1712836.

11. Rivlin RS. Large elastic deformations of isotropic materials I: fundamental concepts. Philosophical Transitions of the Royal Society of London A. 1948; 240(822):459-490.

12. Peeters FJH and Kussner M. Material law selection in finite element simulation of rubber-like materials and its practical application in the industrial design process. In: Dorfmann A and Muhr A, editors. Constitutive models for rubber. Rotterdam: A. A. Balkema Publishers; 1999. p. 29-36.

13. Yeoh $\mathrm{OH}$. Some form of strain energy functions for rubber. Rubber Chemistry and Technology. 1993; 66(5):754-771. http:// dx.doi.org/10.5254/1.3538343.

14. Renaud C, Cros JM, Feng ZQ and Yang B. The Yeoh model applied to the modeling of large deformation contact/impact problems. International Journal of Impact Engineering. 2009; 36(5):659-666. http://dx.doi.org/10.1016/j.ijimpeng.2008.09.008.
15. Ogden RW. Large deformation isotropic elasticity - on the correlation of theory and experiment for the incompressiblerubberlike solids. Proceedings of the Royal Society of London. Series A, Mathematical and Physical Sciences. 1972; 326(1567):565584. http://dx.doi.org/10.1098/rspa.1972.0026.

16. Ogden RW. Large deformation isotropic elasticity - on the correlation of theory and experiment for the compressible rubberlike solids. Proceedings of the Royal Societyof London A. 1972; 328(1575):567-583. http://dx.doi.org/10.1098/ rspa.1972.0096.

17. Treloar LRG. The physics of rubber elasticity. 2nd ed. Glasgow: Oxford University Press; 1958.

18. Arruda EM and Boyce MC. A three-dimensional constitutive model for the large stretch behaviour of rubber elastic materials. Journal of the Mechanics and Physics of Solids. 1993; 41(2):389412. http://dx.doi.org/10.1016/0022-5096(93)90013-6.

19. American Society for Testing and Materials - ASTM. ASTM Standard D638. Standard test method for tensile properties of plastics. West Conshohocken: ASTM; 2010. Available from: $<$ www.astm.org/Download-D638.pdf $\beta$.Access in: 08/14/2014.

20. Bradley GL, Chang PC and McKenna GB. Rubber modeling using uniaxial test data. Journal of Applied Polymer Science. 2001; 81(4):837-848. http://dx.doi.org/10.1002/app.1503.

21. Siddiqui MZ, Tariq F and Naz N. Application of a two-step digital image correlation algorithm in determining Poisson's ratio of metals and composites. In: 62nd International Astronautical Congress; 2011; Cape Town, SA. Cape Town: Materials and Structures Symposium; 2011.

22. Palmieri G, Chiappini G, Sasso M and Papalini S. Hyperelastic material characterization by planar tension tests and full-field strain measurement. In: Proceedings of the SEM Annual Conference, 2009; Albuquerque, Mexico. Albuquerque: Society for Experimental Mechanics; 2009.

23. Chevalier L, Calloch S, Hild F and Marco Y. Digital image correlation used to analyze the multiaxial behavior of rubberlike materials. European Journal of Mechanics. A, Solids. 2001; 20(2):169-187. http://dx.doi.org/10.1016/S0997-7538(00)011359 .

24. Charlton DJ, Yang J and Teh KK. A review of methods to characterize rubber elastic behaviour for use in finite element analysis. Rubber Chemistry and Technology. 1993; 67(3):481502. http://dx.doi.org/10.5254/1.3538686.

25. Yeoh $\mathrm{OH}$. Some benchmark problems for FEA from torsional behaviour of rubber. Rubber Chemistry and Technology. 2003; 76(5):1212-1217. http://dx.doi.org/10.5254/1.3547798.

26. Mohan CVR, Ramanathan J, Kumar S and Gupta AVSKS. Characterisation of materials used in flex bearings of large solid rocket motors. Defence Science Journal. 2011; 61(3):264-269. http://dx.doi.org/10.14429/dsj.61.52.

27. Miller K. Testing elastomer for hyperelastic material models in finite element analysis. Ann Arbor: Axel Products; 2000. Axel Products Test and Analysis Report. 